\title{
Radiocarbon and ${ }^{230} \mathrm{Th}$ data reveal rapid redistribution and temporal changes in sediment focussing at a North Atlantic drift
}

\author{
Gesine Mollenhauer ${ }^{\mathrm{a}, *}$, Jerry F. McManus ${ }^{\mathrm{b}, 1}$, Thomas Wagner $^{\mathrm{c}}$, I. Nick McCave ${ }^{\mathrm{d}}$, Timothy I. Eglinton ${ }^{\mathrm{b}}$ \\ a Department of Geosciences, University of Bremen, Klagenfurter Str., 28359 Bremen, Germany \\ b Woods Hole Oceanographic Institution, Woods Hole, MA 02543, USA \\ c School of Civil Engineering and Geosciences, Newcastle University, Newcastle upon Tyne, NE1 7RU, UK \\ d Department of Earth Sciences, University of Cambridge, Cambridge, CB2 3EQ UK
}

\section{A R T I C L E I N F O}

\section{Article history:}

Received 2 July 2010

Received in revised form 10 November 2010

Accepted 11 November 2010

Available online 9 December 2010

Editor: M.L. Delaney

\section{Keywords:}

compound-specific radiocarbon dating alkenones

${ }^{230} \mathrm{Th}_{\mathrm{xs}}$

focussing factors

drift sediments

\begin{abstract}
A B S T R A C T
In locations of rapid sediment accumulation receiving substantial amounts of laterally transported material the timescales of transport and accurate quantification of the transported material are at the focus of intense research. Here we present radiocarbon data obtained on co-occurring planktic foraminifera, marine haptophyte biomarkers (alkenones) and total organic carbon (TOC) coupled with excess Thorium-230 $\left({ }^{230} \mathrm{Th}_{\mathrm{xs}}\right)$ measurements on four sediment cores retrieved in 1649-2879 m water depth from two such high accumulation drift deposits in the Northeast Atlantic, Björn and Gardar Drifts. While ${ }^{230} \mathrm{Th}_{\mathrm{xs}}$ inventories imply strong sediment focussing, no age offsets are observed between planktic foraminifera and alkenones, suggesting that redistribution of sediments is rapid and occurs soon after formation of marine organic matter, or that transported material contains negligible amounts of alkenones. An isotopic mass balance calculation based on radiocarbon concentrations of co-occurring sediment components leads us to estimate that transported sediment components contain up to $12 \%$ of fossil organic matter that is free of or very poor in alkenones, but nevertheless appears to consist of a mixture of fresh and eroded fossil material. Considering all available constraints to characterize transported material, our results show that although focussing factors calculated from bulk sediment ${ }^{230} \mathrm{Th}_{\mathrm{xs}}$ inventories may allow useful approximations of bulk redeposition, they do not provide a unique estimate of the amount of each laterally transported sediment component. Furthermore, our findings provide evidence that the occurrence of lateral sediment redistribution alone does not always hinder the use of multiple proxies but that individual sediment fractions are affected to variable extents by sediment focussing.
\end{abstract}

(c) 2010 Elsevier B.V. All rights reserved.

\section{Introduction}

Marine sediments accumulating at high rates represent a valuable archive of information on the variability of environmental conditions in the past. High temporal resolution records of climate variability are of particular importance in the context of growing awareness of Earth's potential for abrupt and dramatic climate change. The search for highresolution sediments has driven paleoclimate research to focus on the flanks of the ocean basins, where enhanced biological productivity and delivery of terrigenous materials lead to high rates of sediment accumulation, and on drifts where deposition of hemipelagic sediments is focussed by bottom currents and topography (Flood and Hollister, 1974; McCave and Tucholke, 1986). At these drift sites, fine-grained

\footnotetext{
* Corresponding author. Alfred-Wegener-Institute for Polar and Marine Research, Am Handelshafen 12, 27570 Bremerhaven, Germany. Tel.: +49 421218 65070; fax: +494212188942 .

E-mail addresses: Gesine.Mollenhauer@awi.de (G. Mollenhauer), jmcmanus@Ideo.columbia.edu (J.F. McManus), thomas.wagner@ncl.ac.uk (T. Wagner), mccave@esc.cam.ac.uk (I.N. McCave), teglinton@whoi.edu (T.I. Eglinton).

${ }^{1}$ Now at: Lamont-Doherty Earth Observatory, Palisades, NY 10964-8000, USA.
}

material, possibly from distal locations, serves as a diluent that expands the depth-time axis facilitating high temporal resolution paleoclimate reconstruction. However, this high resolution may come at the price of a more complicated sedimentological history that needs to be unraveled to appraise the full potential of these unique sediments (McCave, 2002).

In recent years, a growing number of paleoenvironmental reconstructions have documented the widespread occurrence of sediment redistribution processes in different sedimentological settings (e.g., Kienast et al., 2007; Marcantonio et al., 2001; Turnewitsch et al., 2008). Evidence for lateral transport comes from a range of different approaches, including sediment trap studies (Thomsen et al., 1998), constant-flux proxies such as Helium-3 $\left({ }^{3} \mathrm{He}\right)$ and excess Thorium-230 $\left({ }^{230} \mathrm{Th}_{\mathrm{xs}}\right)$ (Marcantonio et al., 2001), and radiocarbon dating of co-occurring coarse and fine-grained sedimentary constituents (Ohkouchi et al., 2002).

Lateral displacement of sediment by currents generally involves sorting of particles according to their hydrodynamic behavior. As a consequence, selective lateral transport can therefore lead to decoupling of paleoenvironmental records deduced from different particle types and size classes, notably those using relatively coarse-grained foraminiferal shells and organic matter (e.g., molecular proxies. $\delta{ }^{15} \mathrm{~N}$ ) residing predominantly in the fine fraction. If transport occurs over long 
distances, the associated proxy records might not be representative of local environmental conditions (McCave, 2002).

Compound-specific radiocarbon dating has revealed that, in some locations affected by lateral transport, fine-grained organic matter may be substantially pre-aged by the time of deposition (Mollenhauer et al., 2003, 2005; Ohkouchi et al., 2002). The resulting age offsets between fine-grained material containing a substantial amount of transported particles and coarse-grained, predominantly locally formed sediment constituents are particularly pronounced at Bermuda Rise, a North Atlantic sediment drift site (Ohkouchi et al., 2002). As a consequence, great concern was raised regarding the reliability of palaeoenvironmental reconstructions at drift sites using biomarkers or other proxies associated with the sediment fine fraction (McCave, 2002). However, in other locations known to be affected by lateral sediment redistribution, age offsets between fine-grained and coarse-grained sediment particles are negligible (Kusch et al., 2010; Mollenhauer et al., 2006).

The timescales of sediment redistribution and the effects on palaeoenvironmental information appear to be different and strongly dependent on the local sedimentological regime. The composition of sediments in the source region, the local topography (Turnewitsch et al., 2008), and, to a more limited extent restricted mostly to continental margins, the depth at which transport occurs (surface vs. deep-ocean currents), among other factors, are potentially controlling parameters. In order to develop a predictive capability of whether a proxy record obtained at a high accumulation rate site is likely biased by transported and pre-aged material, it is essential to understand these controlling parameters.

Here we present a new data set from a Northeast Atlantic sediment drift, including excess ${ }^{230} \mathrm{Th}$ data and radiocarbon ages of co-occurring planktic foraminifera, total organic matter (TOC) and marine phytoplankton-derived alkenones. Our results show that differences in sediment focussing result in variable age offsets between foraminifera and total organic carbon, implying the addition of pre-aged transported organic matter. However, unlike at Bermuda Rise, age offsets between marine phytoplankton-derived biomarkers and planktic foraminifera are small or negligible. Furthermore, the age offset between total organic matter and planktic foraminifera is variable and increases considerably during the last glacial, implying changes in composition of laterally advected sediments and in its source area.

\section{Study area and sediment cores}

Our study area is located in the Iceland Basin in the Northeast Atlantic Ocean. Within this basin, Iceland-Scotland Overflow water flowing from NE to SW as a Deep Western Boundary Current, results in the formation of large-scale sediment drifts. Björn Drift and Gardar Drift form on the southeastern flank of the Reykjanes Ridge and in the central Iceland Basin, respectively. These sediments consist of material remobilized from the SE Iceland slope (Bianchi and McCave, 2000). Sedimentation rates vary strongly depending on the local current regime and reach values as high as $120 \mathrm{~cm} \mathrm{ka}^{-1}$.

We used sediment samples from ODP Site 984A and 984C drilled during Leg 162 on Björn Drift in about $1650 \mathrm{~m}$ water depth (Jansen et al., 1996). Additional sediments from three box cores (NEAP5B. 11B and $18 \mathrm{~B} ; 38 \mathrm{~cm} .39 \mathrm{~cm}$. and $37 \mathrm{~cm}$ length, respectively) recovered during RRS Charles Darwin cruise 88 (McCave, 1994) were investigated (Table 1; Fig. 1). The locations were chosen on and off the axis of accumulation of the drifts as manifested by the thickness of Holocene sediments at the respective sites (Bianchi and McCave, 2000).

\section{Methods}

\subsection{Radiocarbon analyses}

Radiocarbon dating was performed at the National Ocean Sciences Accelerator Mass Spectrometry (NOSAMS) facility at the Woods Hole
Table 1

Core locations and estimated thickness of Holocene sediment sequence (NEAP cores: see (Bianchi and McCave, 2000)).

\begin{tabular}{lllll}
\hline Core & $\begin{array}{l}\text { Latitude } \\
(\mathrm{N})\end{array}$ & $\begin{array}{l}\text { Longitude } \\
(\mathrm{W})\end{array}$ & $\begin{array}{l}\text { Water depth } \\
(\mathrm{m})\end{array}$ & $\begin{array}{l}\text { Holocene thickness } \\
(\mathrm{m})\end{array}$ \\
\hline ODP984 & $61^{\circ} 26^{\prime}$ & $24^{\circ} 5^{\prime}$ & 1649 & 2.7 \\
NEAP 5B & $61^{\circ} 04.50^{\prime}$ & $24^{\circ} 31.76^{\prime}$ & 1826 & 2 \\
NEAP 11B & $59^{\circ} 45.49^{\prime}$ & $22^{\circ} 39.24^{\prime}$ & 2484 & 0.5 \\
NEAP 18B & $54^{\circ} 41.56^{\prime}$ & $28^{\circ} 21.02^{\prime}$ & 2879 & 2 \\
\hline
\end{tabular}

Oceanographic Institution, USA. Accelerator mass spectrometer (AMS) radiocarbon ages were determined on TOC and planktic foraminifera for each core-top and core-bottom box core sample. Radiocarbon ages of TOC and planktic foraminifera were also obtained for six depth intervals of ODP core 984A (Table 2). Additional TOC and foraminifera radiocarbon analyses were performed on ODP 984C. These analyses were done using standard procedures for TOC and foraminifera (McNichol et al., 1994). Briefly, subsamples of homogenized bulk sediments containing approximately $1 \mathrm{mg}$ of organic carbon were hydrolyzed with $10 \%$ hydrochloric acid and combusted in evacuated, pre-combusted quartz tubes with copper oxide and silver. Resulting carbon dioxide $\left(\mathrm{CO}_{2}\right)$ was purified and graphitized over an iron catalyst; graphite targets were then pressed for AMS analysis. Aliquots of $\mathrm{CO}_{2}$ gas were used for stable carbon isotopic determination using a VG Prism mass spectrometer. Planktic foraminifera were picked from the $>150 \mu \mathrm{m}$ fraction of wet-sieved subsamples of solvent-extracted sediment residues. For each sample, the most abundant shallow-dwelling species was chosen ( $G$. bulloides in Holocene sediments, N. pachyderma in glacial section; Table 2). Foraminifera samples were hydrolyzed in phosphoric acid, and resulting $\mathrm{CO}_{2}$ gas was treated as previously described.

Abundance permitting, molecular-level radiocarbon dates were obtained on alkenones as a compound class ( $C_{37}, C_{38}$ and $C_{39}$ alkenones). Samples containing sufficient alkenones for radiocarbon analyses included those from the Holocene section of ODP 984A as well as the core-bottoms of NEAP 5B and NEAP 11B (Table 2). Alkenone samples were purified from total lipid extracts of $37-107 \mathrm{~g}$ of freeze-dried homogenized sediments employing the methods of (Ohkouchi et al., 2005). Samples were extracted using a Soxhlet apparatus ( $48 \mathrm{~h}$, dichloromethane:methanol 93:7 v:v) or a Dionex Accelerated Solvent Extractor (dichloromethane:methanol, 9:1 v:v). Extracts were subjected to a sequence of wet-chemical techniques including saponification, silica gel chromatography, urea adduction and silver nitrate/silica gel chromatography. Yields and sample purities were checked with a gas chromatograph equipped with a flame ionization detector (GC/FID). Purified alkenone fractions were quantified with behenic acid myristyl ester as an external standard. The samples comprising $\mathrm{C}_{37^{-}}, \mathrm{C}_{38^{-}}$, and $\mathrm{C}_{39}$-alkenones were subsequently sealed with copper oxide in precombusted evacuated quartz tubes, and then combusted at $850^{\circ} \mathrm{C}$ overnight. Resulting $\mathrm{CO}_{2}$ gas was purified, quantified and converted to graphite with cobalt as a catalyst for radiocarbon analysis by AMS. Alkenone samples yielded $26-210 \mu$ g carbon and were analyzed using dedicated techniques for small samples (Pearson et al., 1998).

Results of radiocarbon measurements are reported as radiocarbon concentrations $\left({ }^{14} \mathrm{C}\right)$ and conventional radiocarbon ages (Stuiver \& Polach, 1977). Conventional radiocarbon ages of co-occurring sediment constituents were compared without prior radiocarbon age calibration. However, foraminiferal ages were calibrated using the online calibration tool CALIB 6.0 (Reimer et al., 2009) and the MARINE09 calibration curve. Highest probability ages (rounded to the nearest 10 from 0 to $10,000 \mathrm{a}$ $\mathrm{BP}$ and to the nearest 50 from 10,000 to 25,000 a BP) were reported as the calibrated age. These calibrated radiocarbon ages are considered to provide the best estimate of depositional age of the sediment and are used for the calculation of sediment focussing factors (see later discussion). 


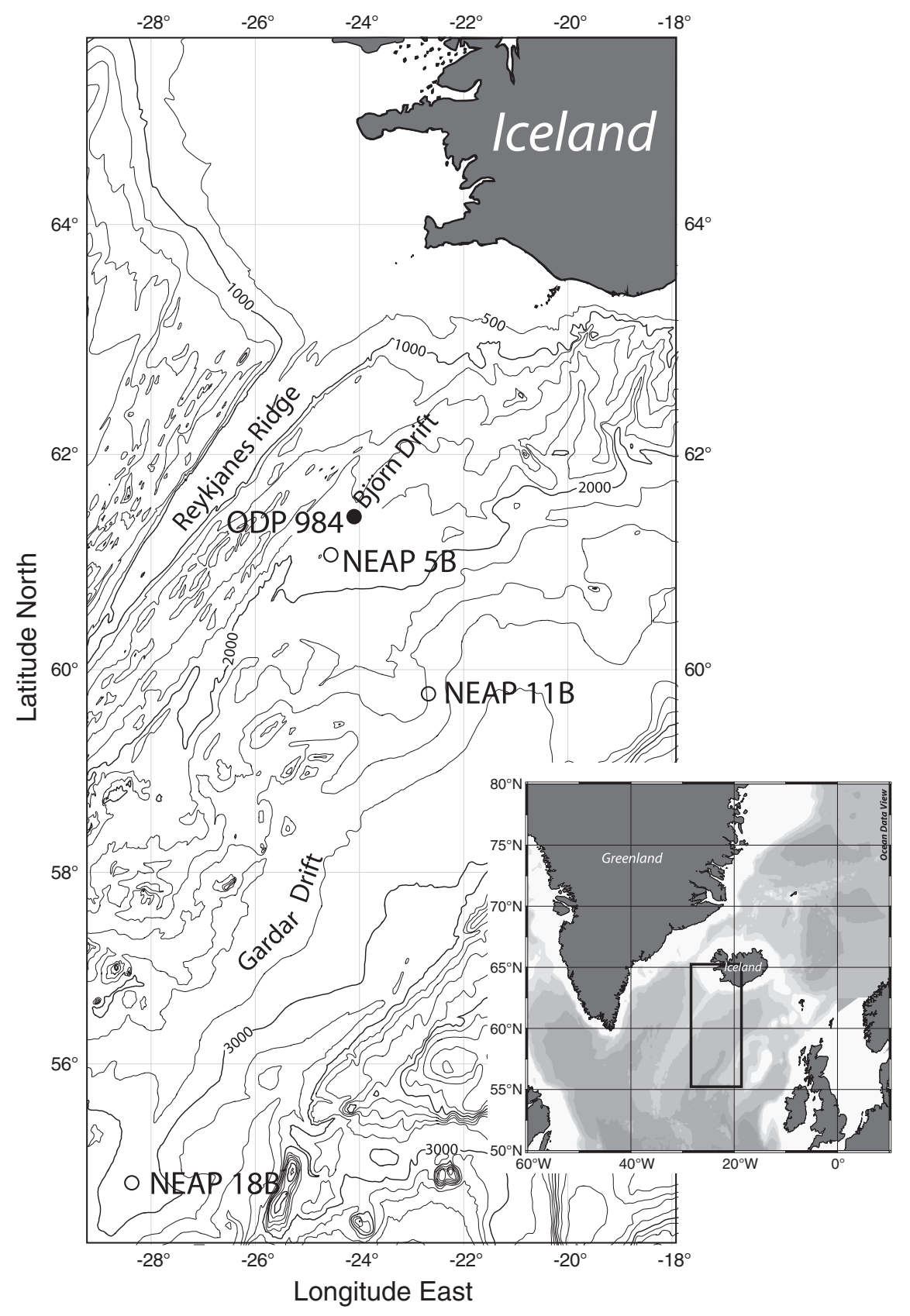

Fig. 1. Study area and core locations. Depth contours (black lines: 1000 m. 2000 m. 3000 m) are at 200 m intervals below 1000 m.

\subsection{Uranium-series analyses}

For Uranium (U)-series isotope analyses, 0.3 to $0.4 \mathrm{mg}$ of dried and homogenized sediment samples from NEAP 5B, 11B, 18B, and ODP 984A were spiked with ${ }^{229} \mathrm{Th}$ and dissolved by acid digestion in nitric acid $\left(\mathrm{HNO}_{3}\right)$, perchloric acid $\left(\mathrm{HClO}_{4}\right)$ and hydrofluoric acid (HF). The acid digested samples were processed by a procedure for separation of Th fractions by anion exchange described by (Choi et al., 2001). Briefly, U-series isotopes were extracted from the total acid digested sample by co-precipitation with iron oxy-hydroxides (3 times). Precipitates were recovered by centrifugation and decantation and re-dissolved in hydrochloric acid $(\mathrm{HCl})$. Small aliquots for the determination of ${ }^{238} \mathrm{U} /{ }^{232} \mathrm{Th}$ ratios were taken and the remaining solution was eluted with $12 \mathrm{~mL}$ of $9 \mathrm{~N} \mathrm{HCl}$ from an anion exchange column packed with AG1-X8 resin. Th-containing fractions were evaporated to a small volume and passed though a second anion exchange column using $8 \mathrm{~N} \mathrm{HNO}_{3}$. Purified solutions were evaporated to a small drop, stored in a Teflon screw cap vial and diluted with $0.3 \mathrm{~mL}$ MilliQ water prior to analysis by ICP/MS (Finnigan MAT Element). Concentrations of ${ }^{230} \mathrm{Th}$ were calculated from the ${ }^{230} \mathrm{Th} /$ ${ }^{229}$ Th ratio (for method details see Choi et al., 2001). Background corrections were based on analysis of method and column blanks. Excess ${ }^{230} \mathrm{Th}$ corrected for contribution of ${ }^{230} \mathrm{Th}$ derived from decay of detrital ${ }^{238} \mathrm{U}$ was estimated from the measured concentration of ${ }^{232} \mathrm{Th}$ in the sediment and an assumed average activity ratio of detrital ${ }^{238} \mathrm{U}$ to ${ }^{232} \mathrm{Th}$ of $\mathrm{R}=0.5$ (Henderson and Anderson, 2003; McManus et al., 1998). A correction for radioactive decay of the unsupported ${ }^{230} \mathrm{Th}$ with a half-life of $75.7 \mathrm{ka}$ is made based on the calibrated foraminiferal radiocarbon ages (François et al., 2004). Ingrown ${ }^{230} \mathrm{Th}$ from decay of authigenic ${ }^{234} \mathrm{U}$ is estimated from an assumed activity ratio of ${ }^{234} \mathrm{U}$ and ${ }^{238} \mathrm{U}$ of 1.14 and from the decay equation and the measured radiocarbon sediment age. The resulting corrected values 
Table 2

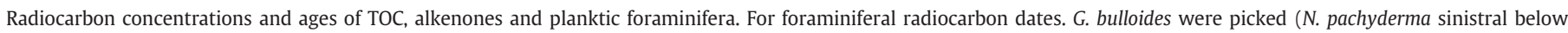
3.55 mbsf (ODP 984 A1A3 samples)).

\begin{tabular}{|c|c|c|c|c|c|c|c|c|c|c|c|}
\hline \multirow[t]{3}{*}{ Core } & \multirow{3}{*}{$\begin{array}{l}\text { Depth interval } \\
(\mathrm{cm})\end{array}$} & \multirow{3}{*}{$\begin{array}{l}\text { Depth } \\
\text { (mbsf) }\end{array}$} & \multirow{3}{*}{$\begin{array}{l}\delta^{13} \mathrm{C}_{\mathrm{org}} \\
(\% \circ \mathrm{PDB})\end{array}$} & \multirow{3}{*}{$\begin{array}{l}\text { TOC } \\
(\% \circ)\end{array}$} & \multirow{3}{*}{$\begin{array}{l}\frac{\Delta{ }^{14} \mathrm{C}}{\text { Alkenones }} \\
(\%)\end{array}$} & \multirow{3}{*}{$\begin{array}{l}\text { Foraminifera } \\
(\%)\end{array}$} & \multicolumn{3}{|c|}{ Conventional radiocarbon age } & \multirow{2}{*}{\multicolumn{2}{|c|}{$\begin{array}{l}\text { Calibrated age } \\
\text { Foraminifera } \\
(\mathrm{yr} \mathrm{BP})\end{array}$}} \\
\hline & & & & & & & \multirow[t]{2}{*}{$\begin{array}{l}\text { TOC } \\
\text { (yr BP) }\end{array}$} & \multirow[t]{2}{*}{$\begin{array}{l}\text { Alkenones } \\
\text { (yr BP) }\end{array}$} & \multirow[t]{2}{*}{$\begin{array}{l}\text { Foraminifera } \\
\text { (yr BP) }\end{array}$} & & \\
\hline & & & & & & & & & & $1 \sigma$ range & age \\
\hline ODP984A1W1 & $50-60$ & 0.55 & -22.1 & -298.5 & -262.9 & -237.6 & $2790 \pm 45$ & $2400 \pm 100$ & $2120 \pm 30$ & $1659-1767$ & 1700 \\
\hline ODP984A1W1 & $100-110$ & 1.05 & -22.6 & -414.4 & -368.0 & -369.6 & $4240 \pm 160$ & $3630 \pm 110$ & $3650 \pm 35$ & $3495-3608$ & 3560 \\
\hline ODP984A1W2 & $50-60$ & 2.05 & -22.5 & -616.4 & -589.7 & -580.8 & $7640 \pm 50$ & $7100 \pm 120$ & $6930 \pm 45$ & $7402-7486$ & 7420 \\
\hline ODP984A1W2 & $100-110$ & 2.55 & -22.9 & -704.4 & -666.3 & -662.2 & $9740 \pm 50$ & $8760 \pm 140$ & $8660 \pm 50$ & $9272-9406$ & 9360 \\
\hline ODP984A1A3 & $50-60$ & 3.55 & -23.9 & -896.8 & & -862.3 & $18,200 \pm 95$ & & $15,850 \pm 75$ & $18,589-18,741$ & 18,650 \\
\hline ODP984A1A3 & $100-110$ & 4.05 & -23.9 & -935.8 & & -902.8 & $22,000 \pm 200$ & & $18,650 \pm 100$ & $21,575-21,996$ & 21,700 \\
\hline NEAP 5B & surface & & -21.0 & -153.0 & & -91.3 & $1280 \pm 30$ & & $715 \pm 30$ & 312-406 & 355 \\
\hline NEAP 5B & $36-38$ & & -21.8 & -268.6 & -285.2 & -232.4 & $2460 \pm 25$ & $2640 \pm 360$ & $2070 \pm 25$ & 1589-1694 & 1645 \\
\hline NEAP 11B & surface & & -21.2 & -212.2 & & -213.5 & $1860 \pm 25$ & & $1880 \pm 25$ & $1380-1471$ & 1405 \\
\hline NEAP 11B & $37-39$ & & -22.1 & -643.3 & -655.4 & -645.9 & $8230 \pm 40$ & $8510 \pm 310$ & $8290 \pm 35$ & $8785-8940$ & 8870 \\
\hline NEAP $18 B$ & surface & & -21.3 & -196.4 & & -88.4 & $1700 \pm 40$ & & $690 \pm 30$ & 289-375 & 310 \\
\hline NEAP 18B & $35-37$ & & -21.4 & -291.9 & & -253.9 & $2720 \pm 35$ & & $2300 \pm 30$ & 1867-1953 & 1905 \\
\hline
\end{tabular}

${ }^{230} \mathrm{Th}_{\mathrm{xs} 0}$ are then used for calculation of focussing factors $(\Psi)$ and sediment fluxes, employing the equations given in François et al. (2004). Focussing factors for core intervals were calculated from ${ }^{230} \mathrm{Th}_{\mathrm{xs} 0}$ inventories divided by the production of ${ }^{230} \mathrm{Th}$ in the overlying water column. For this calculation the mean of the ${ }^{230} \mathrm{Th}_{\mathrm{xs} 0}$ values measured at the top and bottom of these intervals and their respective calibrated foraminiferal radiocarbon ages as age control were used as well as dry bulk density estimated at $0.5 \mathrm{~g} \mathrm{~cm}^{-3}$ for all samples based on shipboard measurements on parallel ODP core 984B (Jansen et al., 1996). Values of $\Psi>1$ imply the occurrence of sediment focussing by addition of laterally supplied material, while exclusive particle supply by vertical settling would result in a $\Psi$ of 1 , and $\Psi<1$ indicates some erosion.

\section{Results}

Radiocarbon ages of planktic foraminifera, TOC and alkenones from ODP984 samples generally increase with depth (Tables 2 and 3, Fig. 2). The lowermost foraminifera sample at 5.05 mbsf sample is 23.1 conventional radiocarbon ka old $\left({ }^{14} \mathrm{C}\right.$ ka hereafter). In the uppermost $3 \mathrm{mbsf}$, roughly corresponding to the Holocene core section, foraminifera and alkenone conventional radiocarbon ages agree within $1 \sigma$ errors ( $2 \sigma$ for the uppermost sample), whereas TOC is on average $900 \mathrm{yr}$ older than co-occurring foraminifera. Below $3 \mathrm{mbsf}$, age differences between foraminifera and TOC are more variable and significantly greater (up to $5850 \mathrm{yr}$ ). Unfortunately, alkenone concentrations were too low in this sediment interval to permit radiocarbon dating.

Table 3

\begin{tabular}{|c|c|c|c|c|c|c|c|}
\hline \multirow[t]{3}{*}{ Core } & \multirow{3}{*}{$\begin{array}{l}\text { Depth interval } \\
(\mathrm{cm})\end{array}$} & \multirow{3}{*}{$\begin{array}{l}\text { Depth } \\
\text { (mbsf) }\end{array}$} & \multirow{3}{*}{$\begin{array}{l}\delta^{13} \mathrm{C}_{\mathrm{org}} \\
\% \text { VPDB }\end{array}$} & \multicolumn{2}{|c|}{ Conventional radiocarbon age } & \multirow{2}{*}{\multicolumn{2}{|c|}{$\begin{array}{l}\text { Calibrated age } \\
(\mathrm{yr} \mathrm{BP})\end{array}$}} \\
\hline & & & & \multirow{2}{*}{$\begin{array}{l}\text { TOC } \\
\text { (yr BP) }\end{array}$} & \multirow{2}{*}{$\begin{array}{l}\text { Foraminifera } \\
(\mathrm{yr} \mathrm{BP})\end{array}$} & & \\
\hline & & & & & & $1 \sigma$ range & Age \\
\hline ODP984C1H1 & $28-30$ & 0.28 & -22.0 & 2120 & & & \\
\hline ODP984C1H1 & $30-32$ & 0.30 & & & $1440 \pm 35$ & 940-1029 & 970 \\
\hline ODP984C1H1 & $58-60$ & 0.59 & & & $2200 \pm 40$ & $1743-1854$ & 1810 \\
\hline ODP984C1H1 & $60-62$ & 0.60 & -22.6 & 3170 & & & \\
\hline ODP984C1H1 & $94-96$ & 0.95 & -22.7 & 4430 & $3690 \pm 40$ & $3550-3667$ & 3610 \\
\hline ODP984C1H1 & $120-122$ & 1.21 & -23.0 & 5220 & & & \\
\hline ODP984C1H1 & $122-124$ & 1.23 & & & $4380 \pm 40$ & $4441-4576$ & 4520 \\
\hline ODP984C1H2 & $12-14$ & 1.63 & & & $5670 \pm 45$ & $6009-6148$ & 6095 \\
\hline ODP984C1H2 & $14-16$ & 1.64 & -22.6 & 6460 & & & \\
\hline ODP984C1H2 & $44-46$ & 1.94 & -23.1 & 7740 & $6830 \pm 65$ & 7293-7412 & 7370 \\
\hline ODP984C1H2 & 64-66 & 2.14 & -23.3 & 8680 & $7390 \pm 50$ & $7808-7919$ & 7850 \\
\hline ODP984C1H2 & $103-104$ & 2.535 & & & $8730 \pm 55$ & $9354-9473$ & 9420 \\
\hline ODP984C1H2 & $104-106$ & 2.54 & -23.3 & 9790 & & & \\
\hline ODP984C1H2 & $123-124$ & 2.735 & & & $9360 \pm 45$ & $10,161-10,237$ & 10,200 \\
\hline ODP984C1H2 & $124-126$ & 2.74 & -24.2 & 10,350 & & & \\
\hline ODP984C1H2 & $133-134$ & 2.835 & & & $9410 \pm 55$ & $10,187-10,319$ & 10,250 \\
\hline ODP984C1H2 & $134-136$ & 2.84 & -24.1 & 10,350 & & & \\
\hline ODP984C1H2 & $144-146$ & 2.94 & -23.6 & 11,150 & $11,600 \pm 55$ & $13,056-13,187$ & 13,100 \\
\hline ODP984C1H3 & 8-10 & 3.08 & -24.0 & 14,750 & $11,650 \pm 110$ & $13,064-13,277$ & 13,150 \\
\hline ODP984C1H3 & $34-36$ & 3.34 & -23.8 & 17,000 & $15,500 \pm 60$ & $18,088-18,298$ & 18,200 \\
\hline ODP984C1H3 & $44-46$ & 3.44 & -24.2 & 20,800 & $16,250 \pm 90$ & $18,795-19,377^{a}$ & 18,900 \\
\hline ODP984C1H3 & $80-82$ & 3.8 & -24.0 & 21,600 & $17,850 \pm 100$ & $20,486-21,008$ & 20,700 \\
\hline ODP984C1H3 & $104-106$ & 4.04 & -23.8 & 19,950 & $18,500 \pm 80$ & $21,402-21,746$ & 21,500 \\
\hline ODP984C1H3 & $140-142$ & 4.4 & -24.9 & 25,800 & $19,950 \pm 80$ & $23,217-23,626$ & 23,400 \\
\hline ODP984C1H4 & 8-10 & 4.58 & -24.0 & 21,600 & & & \\
\hline ODP984C1H4 & $14-16$ & 4.65 & & & $21,000 \pm 90$ & $24,417-24,779$ & 24,500 \\
\hline ODP984C1H4 & $40-42$ & 4.9 & -24.9 & 22,400 & $23,100 \pm 100$ & $26,877-27909^{\mathrm{a}}$ & \\
\hline ODP984C1H4 & $54-56$ & 5.05 & & & $23,100 \pm 110$ & $26,870-27915^{\mathrm{a}}$ & \\
\hline
\end{tabular}

\footnotetext{
a $2 \sigma$ range.
} 

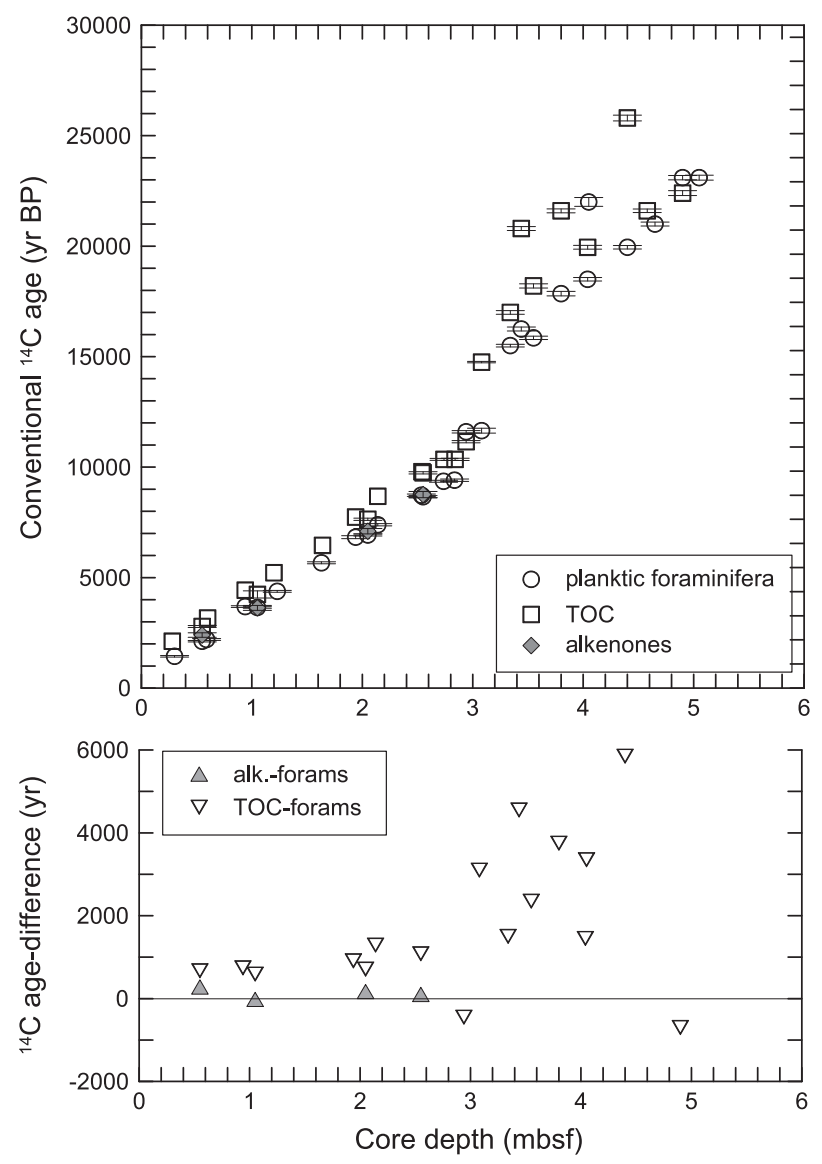

Fig. 2. Conventional radiocarbon ages of ODP site 984 (upper panel) and age differences between organic sediment constituents (TOC, alkenones) and planktic foraminifera (lower panel). Error bars in upper panel denote $1 \sigma$ errors of conventional ${ }^{14} \mathrm{C}$ ages.

NEAP cores $5 \mathrm{~B}$ and $18 \mathrm{~B}$ span only the past 2.0 and $2.3{ }^{14} \mathrm{C} \mathrm{ka}$, respectively, whereas NEAP $11 \mathrm{~B}$ covers $8.3{ }^{14} \mathrm{C}$ ka (Fig. 3). In the two cores from high accumulation rate sites (5B and 18B), TOC is 390 to 1020 ${ }^{14} \mathrm{C}$ yr older than co-occurring foraminifera, while TOC and foraminifera ages at $11 \mathrm{~B}$ were identical within error. Compound abundance only allowed alkenone radiocarbon dates at the core-bottoms of $5 \mathrm{~B}$ and $11 \mathrm{~B}$, which agreed with foraminifera ages within $2 \sigma$ and $1 \sigma$ error margins, respectively.

Concentrations of ${ }^{230} \mathrm{Th}_{\mathrm{xs}}$ as well as sediment focussing factors $(\Psi)$ and fluxes are presented in Table 4. Stations NEAP5B and 18B are characterized by high sedimentation rates. Holocene $\Psi$ values of 4.7 were calculated at both sites. In contrast, $\Psi$ for the low accumulation rate core NEAP 11B was 0.6. ${ }^{230} \mathrm{Th}_{\mathrm{xs}}$-corrected sediment fluxes ranged from $2.4 \mathrm{~g} \mathrm{~m}^{-2} \mathrm{yr}^{-1}$ at the deepest site NEAP $18 \mathrm{~B}$ to $4.1 \mathrm{~g} \mathrm{~m}^{-2} \mathrm{yr}^{-1}$ at NEAP 11B.

The highest focussing factors were calculated for the upper $2 \mathrm{mbsf}$ of ODP984 reaching $\Psi$ values of 4.5 to 5.1 . Normalized fluxes of 2.4-3.3 $\mathrm{g} \mathrm{m}^{-2} \mathrm{yr}^{-1}$ are similar to those at nearby site NEAP 5B. In contrast, normalized vertical fluxes during the glacial were higher (3.3$3.7 \mathrm{~g} \mathrm{~m}^{-2} \mathrm{yr}^{-1}$ ), while sediment focussing appears to have been lower ( $\Psi=1.7-2.4)$. It has to be noted, though, that the deep circulation of the modern North Atlantic leads to an export of a proportion of ${ }^{230} \mathrm{Th}$ produced in the water column that is estimated to be between $10 \%$ and as much as 50\% (Yu et al., 1996; Volger et al., 1998). This phenomenon has important implications for calculated $\Psi$, which would be depressed by a commensurate amount, resulting in an underestimate of lateral contribution to the sediment in the Holocene. Moreover, deep-ocean ventilation likely has varied over the $20 \mathrm{ky}$ timescale of our study. To the extent that the intermediate-depth circulation may have been stronger in the past, the observed differences in $\Psi$ between Holocene and glacial sediment might in part be explained by these effects. However, recent evidence suggests that there was little difference between the strength of the Holocene and glacial circulation at our study location (Praetorius et al., 2008).

\section{Discussion}

\subsection{Age relationships between planktic foraminifera and alkenones}

After the discovery of large age offsets between co-occurring planktic foraminifera and alkenones at Bermuda Rise (Ohkouchi et al., 2002), sediment drifts were suspected to be particularly prone to temporal and perhaps even spatial decoupling of fine- and coarsegrained marine constituents deposited at the same time. Unlike at Bermuda Rise, However, alkenone and planktic foraminiferal radiocarbon ages on Björn Drift agree well. This is true both for locations with high sedimentation rates (ODP 984 and NEAP 5B) as well as for the offaxis site with lower sediment accumulation rates, NEAP 11B. At the latter location, currents are expected to be faster, and the sortable silt proxy of the core-top shows this to be the case (Bianchi and McCave, 2000). Combined with the compelling morphological, sedimentological, and radionuclide evidence for the occurrence of sediment focussing at the high accumulation rate sites, these data indicate that if alkenones are affected by sediment redistribution at all, the redistribution processes occur too rapidly to be resolved within the uncertainty range of radiocarbon dating, i.e., within decades after alkenone formation. This finding is in accordance with observations by Jonkers et al. (2010), who deduced from sediment trap data from Gardar Drift that only rapid lateral supply of freshly produced biogenic material can explain the observed high fluxes to the sediment.

Sediment redistribution was shown to be similarly rapid in the Panama Basin (Kusch et al., 2010), another location at which diverse evidence for sediment redistribution from various proxies is available. Similarly, in the Argentine Basin, northward transport of marine organic matter entrained in the Falkland/Malvinas surface current results in spatial decoupling of temperatures inferred from alkenones and foraminifera (Benthien and Müller, 2000; Rühlemann and Butzin, 2006), but no temporal offsets are evident (Mollenhauer et al., 2006). On the other hand, data from continental margin sediments suggest that down-slope transport of resuspended shelf sediments involves pre-aged material resulting in substantial age offsets at sites with organic-rich sediments (Mollenhauer et al., 2005). Taken together, our new and prior published data suggest that redistribution of marine organic matter is a widespread process in the ocean, but the timescales of organic matter transport and sedimentation may vary markedly. Depending on the sedimentological setting, transport occurs over distances ranging from less than a hundred to several thousand kilometers, and advected material can either be fresh or contain pre-aged marine organic matter.

Knowing the factors that determine whether or not temporal and spatial decoupling is likely to occur is of great interest in order to evaluate the suitability of a core site for high-resolution palaeoenvironmental reconstructions using multiple proxies residing in different grain-size fractions. From comparison of the locations so far investigated for temporal and spatial offsets between alkenones and planktic foraminifera some likely factors can be identified.

1) Spatial decoupling of organic proxies compared to foraminifera is to be expected where a strong gradient from high to low productivity is observed along the flow-path of a current. These conditions are met in the Argentine Basin, where the Falkland/Malvinas surface current flows along the South American coast from highly productive Southern Ocean waters to the more oligotrophic subtropical western South Atlantic, and the bottom current flow is in the same sense. A strong productivity gradient also exists between the waters overlying the Laurentian Fan and Scotian Margin and those of the 

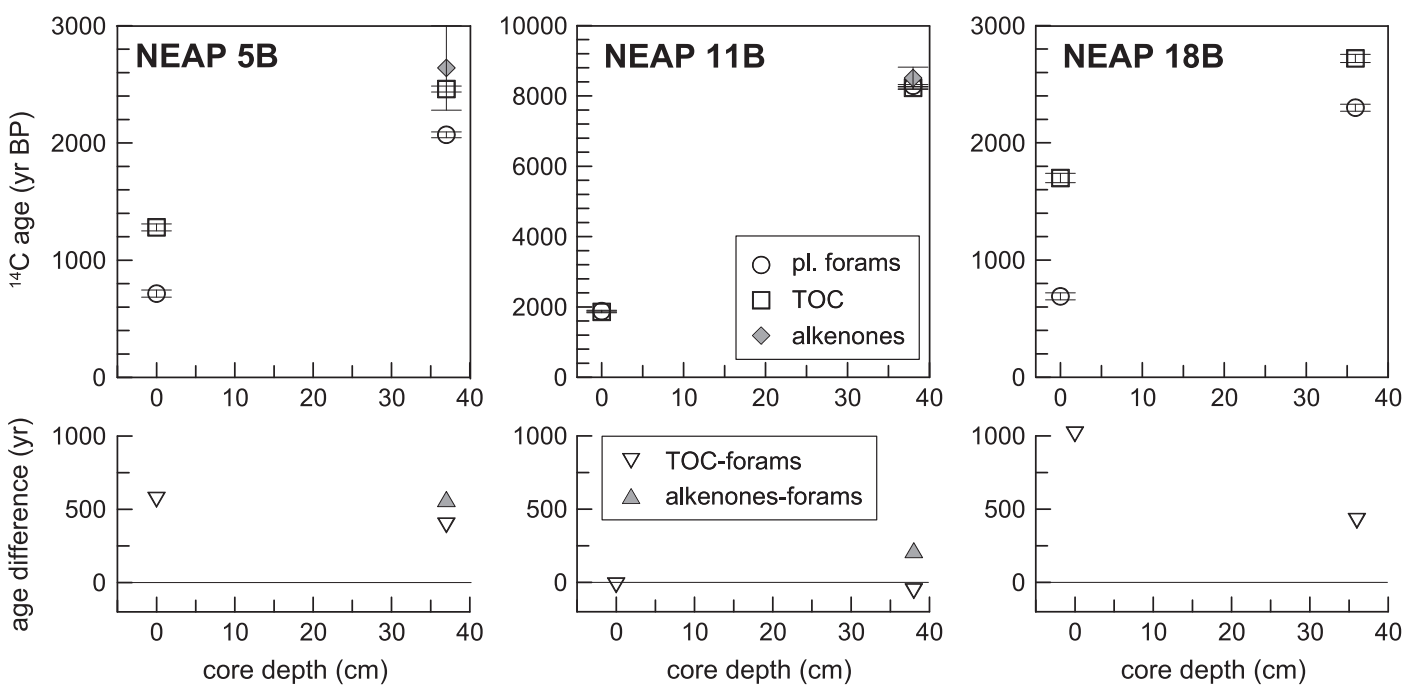

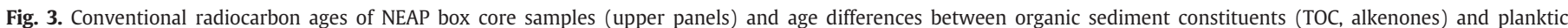

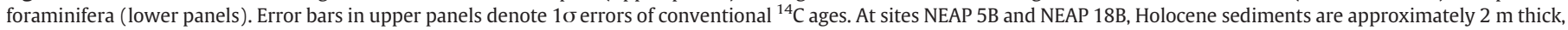
whereas at NEAP $11 \mathrm{~B}$, only $\sim 0.5 \mathrm{~m}$ of Holocene sediments are found. Note the different vertical scales on top panels.

oligotrophic subtropical gyre of the North Atlantic. The former areas are the source for fine-grained sediment deposited at the Bermuda Rise located beneath the oligotrophic gyre regions (Englebrecht and Sachs, 2005). However, this material is transported by the deepwestern boundary current and is likely predominantly resuspended following benthic storm events (Hollister and McCave, 1984). Since the transported material is resuspended, it contains considerable amounts of pre-aged marine organic matter, which results in large age offsets between foraminifera and alkenones. At the continental margins of Southwest Africa and Southwest South America, age offsets between foraminifera and alkenones have been explained by down-slope transport of organic-rich resuspended sediments, probably caused by internal tides (Mollenhauer et al., 2003; Mollenhauer et al., 2005). In contrast to the Argentine Basin and the Bermuda Rise, the transported material deposited at these continental margins sites is likely derived from sources only a few tens of kilometers apart from the sites of deposition.

2) The two locations where no significant age offsets between foraminifera and alkenones are observed despite strong evidence for sediment focussing, i.e., the Panama Basin (Kusch et al., 2010), and the Björn and Gardar Drift area investigated in this study, both

Table 4

${ }^{230} \mathrm{Th}_{\mathrm{xs}}$ corrected for decay and assuming a ${ }^{238} \mathrm{U} /{ }^{232} \mathrm{Th}$ ratio of $R=0.5$, sediment focussing factors assuming dry bulk density of $0.5 \mathrm{~g} \mathrm{~cm}^{-3}$, and ${ }^{230} \mathrm{Th}$ normalized sediment fluxes.

\begin{tabular}{llrlll}
\hline Core & $\begin{array}{l}\text { Depth } \\
\text { interval } \\
(\mathrm{cm})\end{array}$ & $\begin{array}{l}\text { Calibrated } \\
\text { age }\end{array}$ & $\begin{array}{l}{ }^{230} \mathrm{Th}_{\mathrm{xs0}} \\
(\mathrm{dpm} / \mathrm{g})\end{array}$ & $\begin{array}{l}\text { Focussing } \\
\text { factor } \\
\Psi\end{array}$ & $\begin{array}{l}\text { Normalized } \\
\text { flux } \\
\left(\mathrm{g} \mathrm{m}^{-2} \mathrm{yr}^{-1}\right)\end{array}$ \\
\hline ODP984A1W1 & $50-60$ & 1700 & 1.36 & 4.5 & 3.2 \\
ODP984A1W1 & $100-110$ & 3560 & 1.57 & 5.1 & 2.8 \\
ODP984A1W2 & $50-60$ & 7420 & 1.87 & 5.1 & 2.4 \\
ODP984A1W2 & $100-110$ & 9360 & 1.62 & 1.7 & 2.7 \\
ODP984A1A3 & $50-60$ & 18,650 & 1.20 & 2.4 & 3.7 \\
ODP984A1A3 & $100-110$ & 21,700 & 1.34 & & 3.3 \\
NEAP 5B & surface & 355 & 1.64 & 4.7 & 3.0 \\
NEAP 5B & $36-38$ & 1645 & 1.58 & & 3.1 \\
NEAP 11B & surface & 1405 & 1.61 & 0.6 & 4.1 \\
NEAP 11B & $37-39$ & 8870 & 1.77 & & 3.8 \\
NEAP 18B & surface & 310 & 3.06 & 4.7 & 2.4 \\
NEAP 18B & $35-37$ & 1905 & 3.08 & & 2.4 \\
\hline
\end{tabular}

a Focussing factors refer to the interval between this line and the next line (e.g. interval from $50-60 \mathrm{~cm}$ (top) to $100-110 \mathrm{~cm}$ (bottom) in first line). are located in deep-sea basins close to and downstream from the ridges bordering the basins (Carnegie Ridge and Iceland-Faroe Ridge (IFR). respectively). At the same time, in both basins extensive sediment redistribution is documented by morphological and proxy evidence. A speculative hypothesis to explain the lack of temporal decoupling between marine proxies in these regions could be that the ridges and sea mounts in the upstream region of the currents bathing the core sites influence and cause the current regime where, on the one hand, small particles are resuspended rapidly after formation (Turnewitsch et al., 2008), but on the other the same ridges and sea mounts might serve as sediment traps for pre-aged suspended material originating from distal locations on their current-facing sides. Thus the organic components may be transported to the core sites quickly without intermediate storage elsewhere, implying that they likely also only travel over short lateral distances. This was also suggested by Jonkers et al. (2010) to be the case for biogenic material deposited on Gardar Drift. In the Iceland Basin, the IFR furthermore is associated with high productivity (in a region of generally high productivity), which together with the nearby terrestrial sources from Iceland supplies copious amounts of fresh organic matter, potentially swamping any signal from erosion and the redistribution of older sediment eroded from between 1450 and $1800 \mathrm{~m}$ (Thornalley et al., 2010).

\subsection{Age offsets between foraminifera and TOC}

In contrast to alkenones, TOC is systematically older than cooccurring planktic foraminifera at all Björn and Gardar Drift sites with high accumulation rates. At the off-axis site, however. TOC and planktic foraminiferal ages are identical within $1 \sigma$ errors. This implies that at the latter site, TOC consists of larger fractions of fresh material, likely predominantly of marine and perhaps local origin as suggested by the $\delta{ }^{13} \mathrm{C}$ values of -21.2 and $-22.1 \%$, which are slightly more depleted than typical North Atlantic POM values ( $-19 \%$ ) (Hall and McCave, 1998). Taking into account the $\Psi$ value of 0.6 at NEAP $11 \mathrm{~B}$, which argues against deposition of pre-aged transported material at this site, the predominant source of organic matter at this location is likely vertical flux of fresh particles derived from marine primary production, potentially entrained in coarse-grained and densely packed feacal pellets, which cannot easily be resuspended and at the same time provide a high preservation potential for labile organic 
matter. In contrast, the age difference between TOC and foraminifera at the other sites coupled with $\Psi$ values $>4$ in the Holocene results from addition of pre-aged material. Since the alkenones in the same samples agree in age with the foraminifera, the advected pre-aged organic matter is likely free of or very poor in alkenones. The $\delta{ }^{13} \mathrm{C}$ values in the Holocene sediments at the high accumulation rate sites range between -21.0 and $-22.9 \%$, similar to the values at NEAP $11 \mathrm{~B}$, where no sediment focussing is evident and TOC is likely predominantly derived from marine primary production in the overlying surface waters. The combined organic geochemical, stable carbon and radiocarbon isotopic evidence therefore implies redistribution of preaged marine organic matter that contains low to negligible abundances of alkenones. The glacial age (21.7 calibrated ka BP) sediments in ODP 984A do not contain measurable amounts of alkenones. Barents Sea slope sediments older than $14.1 \mathrm{ka}$ BP were found to be free of alkenones (Martrat et al., 2003), and Nordic Sea glacial age sediments are also characterized by generally low alkenone concentrations (Rosell-Melé and Comes, 1999). Therefore, the pre-aged organic matter deposited at sites ODP 984 and NEAP 5B and 18B could derive from glacial-age marine material from near the core site, most likely the erosional southern slope of the IFR and Faroe Bank Channel (Dorn and Werner, 1993), or from a heretofore unidentified source.

\subsection{Amount age and origin of transported organic matter}

In the following discussion, we will first focus only on the most recently deposited sediment (last $2.3 \mathrm{ka}$ ), which allows comparison of all four sites investigated in this study. Here we concentrate on an assessment of the amount and composition of transported organic matter deposited at the core sites using isotopic mass balance calculation:

$\Delta^{14} C_{\text {TOC }}=\left(a \times \Delta^{14} C_{a d v}+b \times \Delta^{14} C_{l o c}\right) /(a+b)$

$\Delta{ }^{14} \mathrm{C}_{\mathrm{TOC}}$ denotes the measured radiocarbon concentration of total organic carbon corrected for the decay since the time of deposition. $\Delta$ ${ }^{14} \mathrm{C}_{\mathrm{adv}}$ is the radiocarbon concentration of the advected and $\Delta{ }^{14} \mathrm{C}_{\text {loc }}$ that of the locally sourced and vertically supplied sediment contribution at the time of deposition, i.e., both values are corrected for the decay that occurred since deposition. Decay-corrected radiocarbon concentrations of TOC and planktic foraminifera can be calculated from measured $\Delta{ }^{14} \mathrm{C}$ values using the equation presented by Ohkouchi et al. (2002). The time of deposition is assumed to be best reflected by the calibrated radiocarbon age of the planktic foraminifera in each sample. Factors $a$ and $b$ are the relative contributions of the advected and local organic matter, respectively. Focussing factors are regarded as a means of quantifying the amount of laterally supplied material (i.e., factor $a$ in Eq. (1)). In a simplified view, a focussing factor of 4.5 indicates deposition of 4.5 times the amount of vertically sinking particles, i.e., that the sediment is composed of one part (23\%) vertically sinking particles and 3.5 parts (77\%) laterally advected material, assuming equal composition of both fluxes and ${ }^{230} \mathrm{Th}$ equilibration of particles with the water depth of the site of deposition (François et al., 2004). If the measured focussing factors are used as an estimate of the amount of laterally supplied pre-aged material, 77 to $79 \%$ of the sediment at the drift site samples of the last $2.3 \mathrm{ka}$ (NEAP sites 5B and 18B and uppermost ODP 984 depth interval) would be transported (factor $a$ ). The average age at the time of deposition of the transported organic matter can then be estimated using the mass balance equation (Eq. 1) and the assumption that the radiocarbon concentration of the vertical flux at the time of deposition $\left(\Delta^{14} C_{\text {loc }}\right)$ equals the decay-corrected radiocarbon concentrations of planktic foraminifera. This assumption is valid if the vertical organic matter flux is composed of marine organic matter produced in the water depth at which the planktic foraminifera thrived. If Eq. (1) is re- arranged and solved for $\Delta{ }^{14} \mathrm{C}_{\mathrm{adv}}$, the ${ }^{14} \mathrm{C}$ age $t$ of the transported organic matter at the time of deposition can be derived as:

$t=-8033 \times \ln \left(\Delta^{14} C_{a d v} / 1000+1\right)$.

Using this mass balance, the average radiocarbon age of transported organic matter at the time of deposition is estimated to range from approximately 1020 to $1750{ }^{14} \mathrm{C}$ yrs in the sediments accumulating during the last $2.3 \mathrm{cal} \mathrm{ka}$.

In a second independent approach, the amount of transported organic matter (a) can be estimated when assuming its age $(t)$ converted to the radiocarbon concentration at the time of deposition by re-arranging Eq. (2) to solve for $\Delta{ }^{14} C_{a d v}$ and using again the mass balance equation (Eq. 1). As before, the assumption is made that the locally sourced organic matter at the time of deposition has a radiocarbon concentration equal to the decay-corrected ${ }^{14} \mathrm{C}$ concentration of the planktic foraminifera. As previously discussed, the pre-aged transported organic matter could consist of glacial age (18 ${ }^{14} \mathrm{C} \mathrm{ka} ; \Delta{ }^{14} \mathrm{C}_{\mathrm{adv}}=-894 \%$ ), or fossil $\left(\Delta{ }^{14} \mathrm{C}_{\mathrm{adv}}=-1000 \%\right)$, marine organic matter. If we assume that glacial age or fossil marine organic matter was the only transported material, only $6-13 \%$ or $5-12 \%$, respectively, of the sediment accumulating at the drift sites would consist of this material.

If we assume homogenous composition of the transported material, the first mass balance calculation requires lateral supply of large amounts of only slightly pre-aged material. Recent work on the particle affinity of ${ }^{230} \mathrm{Th}$ as a function of grain-size and mineralogy suggests that due to preferential sorption on clay-sized particles and hydrodynamic particle sorting during transport, focussing factors based on bulk sediment ${ }^{230} \mathrm{Th}_{\mathrm{xs}}$ inventories tend to overestimate the amount of lateral flux (Kretschmer et al., 2010; McGee et al., 2010). The actual amounts of laterally transported material supplied to the core sites are likely to be somewhat less than suggested by focussing factors calculated from bulk sediment samples. This size-bias would be greatest at NEAP $18 \mathrm{~B}$, where grain-size is finest (Bianchi and McCave, 2000). Therefore we do not regard the estimate of $77-79 \%$ addition of only slightly pre-aged material a plausible scenario.

On the other hand, the estimate of $5-13 \%$ of lateral flux generated by the second mass balance calculation is insufficient to explain the high sedimentation rates at the drift sites. Based on the comparison of Holocene sedimentation rates estimated for the off-axis site NEAP 11B $(5 \mathrm{~cm} / \mathrm{ka})$ and sites NEAP 5B and 18B $(20 \mathrm{~cm} / \mathrm{ka})$ as well as ODP 984 $(27 \mathrm{~cm} / \mathrm{ka})$, a lateral flux of about $75 \%$ of the total flux seems realistic. Therefore, in order to reconcile the ${ }^{230} \mathrm{Th}_{\mathrm{xs}}$ and radiocarbon data, we suggest that the organic sediment supplied laterally to our core sites during the past $2.3 \mathrm{cal} \mathrm{ka}$ is composed of a mixture of fresh local material and $5-13 \%$ organic matter free of or very poor in alkenones and of glacial age or older. As a consequence, alkenone based seasurface temperature reconstructions can be interpreted as local signals given this minor transported bias.

\subsection{Downcore variability in age offsets and focussing factors}

A pronounced difference in the age offsets between foraminifera and TOC exists between the Holocene and glacial age sediments of ODP 984, suggesting that the advected material was derived from different, even older sources during the glacial than the Holocene. Glacial age sediments of ODP 984 are characterized by high and variable age differences between foraminifera and TOC and more ${ }^{13} \mathrm{C}$ depleted stable carbon isotopic composition $\left(\delta{ }^{13} \mathrm{C}\right.$ values ranging between -23.9 and $-24.9 \%$ ). Indeed, all samples with large age offsets show $\delta{ }^{13} \mathrm{C}$ values lower than approximately $-23.5 \%$ (Fig. 4), arguing for advection of pre-aged organic matter, which may include pre-aged terrigenous material or marine organic matter synthesized at low surface water temperatures (Rau et al., 1989). Higher contributions of terrigenous organic matter to total TOC burial during 


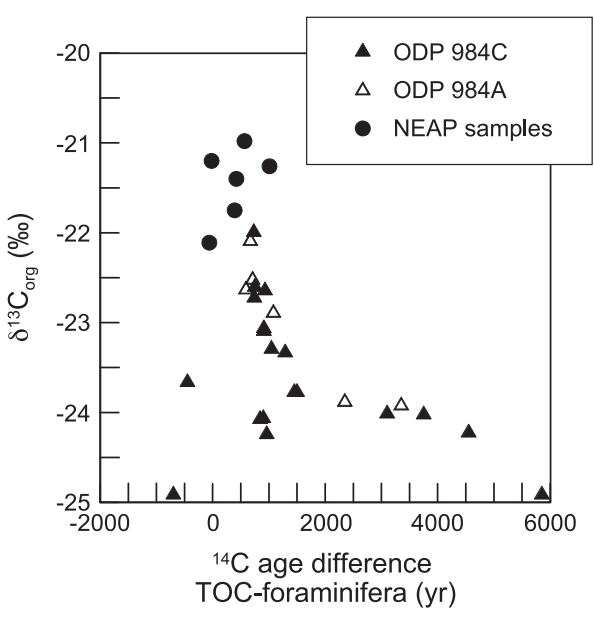

Fig. 4. Differences in conventional radiocarbon ages of TOC and planktic foraminifera plotted against the $\delta^{13} \mathrm{C}$ values of TOC. Age differences of more than $\sim 1000 \mathrm{yr}$ are associated with lower $\delta^{13} \mathrm{C}$ values indicating a significant contribution of pre-aged terrigenous organic matter.

the glacial than the Holocene were also reported by Hall and McCave (1998) for the NW European continental margin. Based on $\mathrm{C}_{\mathrm{org}} / \mathrm{N}$ ratios, these authors argued that increased glacial supply of terrigenous material is the most likely explanation for the observed isotopic trends in the region. Whether the more ${ }^{13} \mathrm{C}$-depleted TOC in glacial and deglacial sediments is caused by admixture of pre-aged terrigenous or "cold" marine organic matter cannot be resolved in this study. This does, however, not affect the interpretation of the ${ }^{14} \mathrm{C}$ data.

The study area is located in higher northern latitudes, which were covered by winter sea-ice during the last glacial maximum (Sarnthein et al., 2003), and adjacent land-masses were glaciated. Therefore, supply of glacial-age terrestrial organic matter to the sediments during the last glacial seems less probable. It is highly likely that glacial erosion of Iceland and the Faroes mobilized much older terrestrial organic matter, e.g., from the last interglacial. If Eemian terrestrial organic matter containing no measurable radiocarbon (i.e., $\Delta{ }^{14} C_{a d v}=-1000 \%$ in Eq. (1)) was supplied to the core location and caused the large age offsets between foraminifera and TOC prior to the early Holocene, mass balance calculation suggests that the relative contribution of this material would be significantly less than $20 \%$ of TOC.

Sediment focussing factors are lower for glacial age sediments than for the Holocene ( $\Psi=1.7$ and 2.4). North Atlantic intermediate water flow speed between 1.1 and $2 \mathrm{~km}$ water depth is reconstructed to be more rapid during the glacial than the Holocene (McCave et al., 1995). Even though data from Björn Drift, where ODP 984 was retrieved, are lacking from the study of McCave et al. (1995), the evidence for increased flow speed at the water depth of site 984 stems from locations directly upstream. It thus appears that increased flow speeds resulted in less sediment focussing at site ODP 984, but advected material contained a greater proportion of pre-aged organic matter than during the Holocene. A change in source of the advected material at ODP984 between the glacial and the Holocene is supported by grain-size data (Praetorius et al., 2008). These authors suggest that, while flow speeds remained at comparable levels between the glacial and the Holocene, advected material during the Holocene was transported over much shorter distances thus implying a more proximal sediment source after the initiation of the IcelandScotland Overflow Waters at the onset of the Holocene.

\section{Conclusions}

Radiocarbon age differences between alkenones and foraminifera in Holocene sediment drifts of the Iceland Basin were negligible, implying that redistribution of sediments within the basin is rapid and occurs soon after formation of marine organic matter, or that transported material contains negligible amounts of alkenones. Pre-aged organic material supplied during the Holocene to the core sites is likely fossil or at least of glacial age but only accounts for less than $12 \%$ of TOC. Our data are consistent with redistribution of particles consisting of a mixture of fresh and pre-aged material. Downcore variations in age offsets between foraminifera and TOC document changes in source area of the transported material between the glacial and the Holocene. Focussing factors based on ${ }^{230} \mathrm{Th}_{\mathrm{xs}}$ cannot be used directly to provide a unique determination of the amount of pre-aged organic matter. However, lateral mixing does not always hinder the use of multiple proxies from a single core in reconstructing palaeoenvironmental change. In order to better constrain source, age and amount of transported material, multiproxy studies including biomarker information on organic matter composition, grain-size spectra of sediments, and multiple isotopes of organic matter should be considered.

\section{Acknowledgements}

Technical support was provided by Alan Fleer, Susan Brown-Leger and Daniel Montluçon. The NOSAMS staff is thanked for the radiocarbon analyses. Thoughtful comments from two anonymous reviewers helped improve the manuscript. This work was funded by NSF grant \# OCE0327405 and a WHOI-NOSAMS postdoctoral scholarship as well as a HGF young investigators group grant to GM. The work was also supported in part by NSF grants \#OCE 0549111 and \#OCE 0840430 and an award from the Comer Research and Education Foundation to JFM. TW gratefully acknowledges the Royal Society-Wolfson Research Merit Award.

\section{References}

Benthien, A., Müller, P.J., 2000. Anomalously low alkenone temperatures caused by lateral particle and sediment transport in the Malvinas Current region, western Argentine Basin. Deep Sea Res. I 47, 2369-2393.

Bianchi, G.G., McCave, I.N., 2000. Hydrography and sedimentation under the deep western boundary current on Björn and Gardar Drifts, Iceland Basin. Mar. Geol. 165, 137-169.

Choi, M.S., François, R., Sims, K., Bacon, M.P., Brown-Leger, S., Fleer, A.P., Ball, L., Schneider, D., Pichat, S., 2001. Rapid determination of ${ }^{230} \mathrm{Th}$ and ${ }^{231} \mathrm{~Pa}$ in seawater by desolvated micro-nebulization inductively coupled plasma magnetic sector mass spectrometry. Mar. Chem. 76, 99-112.

Dorn, W.U., Werner, F., 1993. The contour-current flow along the southern IcelandFaeroe Ridge as documented by its bedforms and asymmetrical channel fillings. Sed. Geol. 82, 47-59.

Englebrecht, A.C., Sachs, J.P., 2005. Determination of sediment provenance at drift sites using hydrogen isotopes and unsaturation ratios in alkenones. Geochim. Cosmochim. Acta 69, 4253-4265.

Flood, R.D., Hollister, C.D., 1974. Current-controlled topography on the continental margin off the eastern United States. In: Burke, C.A., Drake, C.L. (Eds.), The Geology of Continental Margins. Springer Verlag, New York, pp. 197-205.

François, R., Frank, M., Rutgers van der Loeff, M.M., Bacon, M.P., 2004. ${ }^{230}$ Th normalization: an essential tool for interpreting sedimentary fluxes during the late Quaternary. Paleoceanography 19. doi:10.1029/2003PA000939.

Hall, I.R., McCave, I.N., 1998. Glacial-interglacial variation in organic carbon burial on the slope of the N.W. European Continental Margin. Prog. Oceanogr. 42, 37-60.

Henderson, G.M., Anderson, R.F., 2003. The U-series toolbox for paleoceanography. Rev. Mineral. Geochem. 52, 493-531.

Hollister, C.D., McCave, I.N., 1984. Sedimentation under deep-sea storms. Nature 309, $220-225$.

Jansen, E., Raymo, M.E., Blum, P., Al., E., 1996. Proceedings ODP, Initial Reports, 162. Ocean Drilling Program, College Station, TX.

Jonkers, L., Mienis, F., Boer, W., Hall, I.R., Brummer, G.-J.A., 2010. Intra-annual variability of extremely rapid sedimentation onto Gardar Drift in the northern North Atlantic. Deep Sea Res. I 57, 1027-1038.

Kienast, S.S., Kienast, M., Mix, A., Calvert, S.E., François, R., 2007. Thorium-230 normalized particle flux and sediment focusing in the Panama Basin region during the last 30,000 yrs. Paleoceanography 22, PA2213-PA.

Kretschmer, S., Geibert, W., Rutgers van der Loeff, M.M., Mollenhauer, G., 2010. Grain size effects on ${ }^{230} \mathrm{Th}_{\mathrm{xs}}$ inventories in opal-rich and carbonate-rich marine sediments. Earth Planet. Sci. Lett. 294, 131-142.

Kusch, S., Eglinton, T.I., Mix, A., Mollenhauer, G., 2010. Timscales of lateral sediment transport in the Panama Basin as revealed by compound-specific radiocarbon ages of alkenones. Earth Planet. Sci. Lett. 290, 340-350. 
Marcantonio, F., Anderson, R.F., Higgins, S.M., Stute, M., Schlosser, P., Kubik, P., 2001. Sediment focusing in the central equatorial Pacific ocean. Paleoceanography 16 , 260-267.

Martrat, B., Grimalt, J.O., Villanueva, J., van Kreveld, S., Sarnthein, M., 2003. Climatic dependence of the organic matter contributions in the north eastern Norwegian Sea over the last 15, 000 yrs. Org. Geochem. 34, 1057-1070.

McCave, I.N., 1994. Cruise Report, RRS Charles Darwin Cruise 88, NEAPACC. Sciences. Department of Sciences, University of Cambridge. $45 \mathrm{pp}$.

McCave, I.N., 2002. A poisoned chalice? Science 298, 1186-1187.

McCave, I.N., Manighetti, B., Beveridge, N.A.S., 1995. Circulation in the glacial North Atlantic inferred from grain-size measurements. Nature 374, 149-152.

McCave, I.N., Tucholke, B.E., 1986. Deep current-controlled sedimentation in the western North Atlantic. In: Vogt, P.R., Tucholke, B.E. (Eds.), The Geology of North America, Volume M, The Western North Atlantic Region. The Geological Society of America, pp. 451-468.

McGee, D., Marcantonio, F., McManus, J.F., Winkler, G., 2010. The response of excess ${ }^{230} \mathrm{Th}$ and extraterrestrial ${ }^{3} \mathrm{He}$ to sediment redistribution at the Blake Ridge, western North Atlantic. Earth Planet. Sci. Lett. 299, 138-149.

McManus, J.F., Anderson, R.F., Broecker, W.S., Fleisher, M.Q., Higgins, S.M., 1998. Radiometrically determined sedimentary fluxes in the sub-polar North Atlantic during the last 140, 000 yrs. Earth Planet. Sci. Lett. 155, 29-43.

McNichol, A.P., Osborne, E.A., Gagnon, A.R., Fry, B., Jones, G.A., 1994. TIC, TOC, DIC, DOC, PIC, POC - unique aspects in the preparation of oceanographic samples for ${ }^{14} \mathrm{C}$ AMS. Nucl. Instrum. Meth. Phys. Res. B 92, 162-165.

Mollenhauer, G., Eglinton, T.I., Ohkouchi, N., Schneider, R.R., Müller, P.J., Grootes, P.M., Rullkötter, J., 2003. Asynchronous alkenone and foraminifera records from the Benguela upwelling system. Geochim. Cosmochim. Acta 67, 2157-2171.

Mollenhauer, G., Kienast, M., Lamy, F., Meggers, H., Schneider, R.R., Hayes, J.M., Eglinton, T.I., 2005. An evaluation of ${ }^{14} \mathrm{C}$ age relationships between co-occurring foraminifera, alkenones, and total organic carbon in continental margin sediments. Paleoceanography 20, PA1016. doi:10.1029/2004PA001103.

Mollenhauer, G., McManus, J.F., Benthien, A., Müller, P.J., Eglinton, T.I., 2006. Rapid lateral particle transport in the Argentine Basin: molecular ${ }^{14} \mathrm{C}$ and ${ }^{230} \mathrm{Th}_{\mathrm{xs}}$ evidence. Deep Sea Res. I 53, 1224-1243.

Ohkouchi, N., Eglinton, T.I., Hughen, K., Roosen, E., Keigwin, L.D., 2005. Radiocarbon dating of alkenones from marine sediments: III. Influence of solvent extraction procedures on ${ }^{14} \mathrm{C}$ measurements of foraminifera. Radiocarbon 47, 425-432.

Ohkouchi, N., Eglinton, T.I., Keigwin, L.D., Hayes, J.M., 2002. Spatial and temporal offsets between proxy records in a sediment drift. Science 298, 1224-1227.
Pearson, A., McNichol, A., Schneider, R.J., von Reden, K.F., Zheng, Y., 1998. Microscale AMS ${ }^{14} \mathrm{C}$ measurement at NOSAMS. Radiocarbon 40, 61-75.

Praetorius, S.K., McManus, J.F., Oppo, D.W., Curry, W.B., 2008. Episodic reductions in bottom-water currents since the last ice age. Nat. Geosci. 1, 449-452.

Rau, G.H., Takahashi, T., Marais, D.J.D., 1989. Latitudinal variations in plankton [delta] 13C: implications for CO2 and productivity in past oceans. Nature 341, 516-518.

Reimer, P.J., Baillie, M.G.L., Bard, E., Bayliss, A., Beck, J.W., Blackwell, P.G., Bronk Ramsey, C., Buck, C.E Burr G.S, Edwards, R. Friedrich, M., Grootes, P, Guilderson, T., Hajdas, I., Heaton, T.J., Hogg, A.G., Hughen, K.A., Kaiser, K.F., Kromer, B., McCormac, F.G., Manning, S., Reimer, R.W., Richards, D.A., Southon, J.R., Talamo, S., Turney, C.S. M., van der Plicht, J., Weyhenmeyer, C.E., 2009. IntCal09 and Marine09 radiocarbon age calibration curves, $0-50,000$ yrs cal BP. Radiocarbon 51, 1111-1150.

Rosell-Melé, A., Comes, P., 1999. Evidence for a warm Last Glacial Maximum in the Nordic seas or an example of shortcomings in $\mathrm{U}^{\mathrm{K}^{\prime}} 37$ and $\mathrm{U}^{\mathrm{K}}{ }_{37}$ to estimate low sea surface temperature? Paleoceanography 14, 770-776.

Rühlemann, C., Butzin, M., 2006. Alkenone temperature anomalies in the BrazilMalvinas Confluence area caused by lateral advection of suspended particulate material. Geochem. Geophys. Geosystems G3 7, Q10015.

Sarnthein, M., Pflaumann, U., Weinelt, M., 2003. Past extent of sea ice in the northern North Atlantic inferred from foraminiferal paleotemperature estimates. Paleoceanography 18, 1047.

Stuiver, M., Polach, H.A., 1977. Discussion, reporting of ${ }^{14} \mathrm{C}$ data. Radiocarbon 19 , 355-363.

Thomsen, C., Schulz-Bull, D.E., Petrick, G., Duinker, J.C., 1998. Seasonal variability of the long-chain alkenone flux and the effect on the $\mathrm{U}^{\mathrm{k}^{\prime}}{ }_{37}-$ index in the Norwegian Sea. Org. Geochem. 28, 311-323.

Thornalley, D.J.R., Elderfield, H., McCave, I.N., 2010. Intermediate and deep water paleoceanography of the northern North Atlantic over the past 21,000 yrs. Paleoceanography 25, PA1211.

Turnewitsch, R., Reyss, J.-L., Nycander, J., Waniek, J.J., Lampitt, R.S., 2008. Internal tides and sediment dynamics in the deep sea - evidence from radioactive 234Th/238U disequilibria. Deep Sea Res. I 55, 1727-1747.

Volger, S., Scholten, J., Rutgers van der Loeff, M.M., Mangini, A., $1998 .{ }^{230}$ Th in the eastern North Atlantic: the importance of water mass ventilation in the balance of ${ }^{230}$ Th. Earth Planet. Sc. Lett. 156, 51-74.

Yu, E.-F., Francois, R., Bacon, M.P., 1996. Similar rates of modern and last-glacial ocean thermohaline circulation inferred from radiochemical data. Nature 379, 689-694. 